\title{
Magmatismo há ca. 660 - 640 Ma no Domínio Socorro: Registros de Convergência Pré-Colisional na Aglutinação do Gondwana O cidental
}

\author{
Peter Christian Hackspacher ${ }^{1}$ (phack@ rc.unesp.br), Allen Hutcheson Fetter ${ }^{1}$, Hans Dirk Ebert ${ }^{1}$, \\ Valdecir de Assis Janasi ${ }^{2}$, Elton Luiz Dantas ${ }^{3}$, Marcos Aurélio Farias de 0 liveira ${ }^{1}$, \\ Iramaia Furtado Braga ${ }^{1}$, Francisco de Assis Negri ${ }^{4}$ \\ ${ }^{1}$ Departamento de Petrologia e Metalogenia - Instituto de Geociências e Ciências Exatas - UNESP \\ Caixa Postal 178, CEP 13506-900, Rio Claro, SP, BRA \\ 2Departamento de Mineralogia e Geotectônica - Instituto de Geociências - USP, São Paulo, SP, BRA \\ ${ }^{3}$ Departamento de Geologia Geral e Aplicada - Instituto de Geociências, UnB, Brasília, DF, BRA \\ ${ }^{4}$ Instituto Geológico, São Paulo, SP, BRA
}

Palavras-chave: convergência pré-colisional, Neoproterozóico, Província Mantiqueira.

\section{RESUMO}

Idades U-Pb em zircão com valores entre 660 e 640 Ma, obtidas em uma série de ortognaisses e plútons de afinidades cálcio-alcalinas, no sudeste da Província Mantiqueira Central, sugerem que um importante período de magmatismo cordilherano ocorreu nesta região antes da etapa colisional da aglutinação do Gondwana Ocidental (até então reportado ao período entre 625 e $580 \mathrm{Ma}$ ). A natureza isotópica deste magmatismo ainda não foi bem caracterizada, no entanto, alguns dados isotópicos Sm-Nd preliminares sugerem que estes magmas não foram derivados exclusivamente de litosfera paleoproterozóica, mas constituem produtos híbridos de fontes paleoproterozóicas e neoproterozóicas. Tais misturas são comumente observadas em ambiente de arcos continentais. É possível que as rochas com idades entre 660 e 640 Ma representem um magmatismo de arco tipo cordilherano, resultado da subducção de crosta oceânica Neoproterozóica durante a convergência pré-colisional e fechamento de oceano (nesta região de ligação entre Adamastor e Goianides).

Keywords: precollisional convergence, Neoproterozoic, Mantiqueira Province.

\begin{abstract}
Uranium-lead zircon ages between 660 and $640 \mathrm{Ma}$, obtained from a series of calc-alkaline orthogneisses and plutons in southeast Brazil's Central Mantiqueira Province, suggest that a significant period of magmatism occurred in this region prior to the collisional assembly of West Gondwana (presently constrained in the region between $c a .625$ and $580 \mathrm{Ma}$ ). While the nature of this earlier magmatism is presently unclear, some preliminary Sm-Nd data suggest that these magmas were not solely derived from the Paleoproterozoic lithosphere, but appear to represent hybrid products of Paleoproterozoic and Neoproterozoic sources. As such hybrid mixtures have been most commonly observed in continental arc settings, it is possible that the 660 to 640 Ma magmatism represents arc magmatism that resulted from subduction of Neoproterozoic oceanic crust during early precollisional convergence and closure of a branch of either the Adamastor or Goianides oceans.
\end{abstract}




\section{INTRO DU ÇÃO}

A evolução geológica dos sistemas orogênicos a sul do Cráton do São Francisco tem sido explicada através de uma história policíclica que começou no Arqueano e finalizou com a Orogênese Brasiliana durante a aglutinação do Gondwana Ocidental. A reconstrução da evolução précambriana desta região apresenta uma série de dificuldades causadas pela intensa deformação e metamorfismo que as rochas sofreram durante a Orogênese Brasiliana.

Avanços na identificação de etapas desta evolução vêm ocorrendo através do uso da datação pelo método radiométrico U-Pb em zircão e monazita, permitindo a identificação de uma série de eventos de curta duração que ocorreram anteriormente ao pico da principal colisão. O reconhecimento dos eventos neoproterozóicos pré-colisionais na Província Mantiqueira Central é especialmente importante podendo fornecer informações sobre a natureza da convergência anterior à aglutinação final do Gondwana Ocidental.
Estudos geológicos e geocronológicos recentes (Cordani et al., 2000; Vlach, 2001; Negri, 2002; Cordani et al., 2002) têm revelado idades relacionadas a eventos de magmatismo e metamorfismo no intervalo entre 810 a $780 \mathrm{Ma}$, valores estes até então desconhecidos. Inúmeras idades precisas vinculadas ao magmatismo sin- a póscolisional da Orogênese Brasiliana vêm sendo obtidas, permitindo reconstruir uma história evolutiva mais precisa da Província Mantiqueira (Töpfner, 1996; Hackspacher et al., 2000; Janasi et al., 2001).

Interpretações paleogeográficas relacionadas a rochas plutônicas com idades em torno de $c a$. $650 \mathrm{Ma}$ da Faixa Ribeira Central e porção sul da Faixa Brasília ainda são esparsas (Campos Neto, 2000). Neste artigo são apresentados dados de U-Pb em zircão e Sm-Nd em rocha total de rochas plutônicas do Domínio Socorro (Figura 1) e pertencentes aos complexos Piracaia, Socorro e Paraisópolis (Morais et al., 1999). Os resultados isotópicos revelam um período de expressivo magmatismo pré-colisional naquela região, entre 655 e 642 Ma atrás, representando importante etapa do desenvolvimento do Gondwana Ocidental, nesta região, durante o Neoproterozóico.
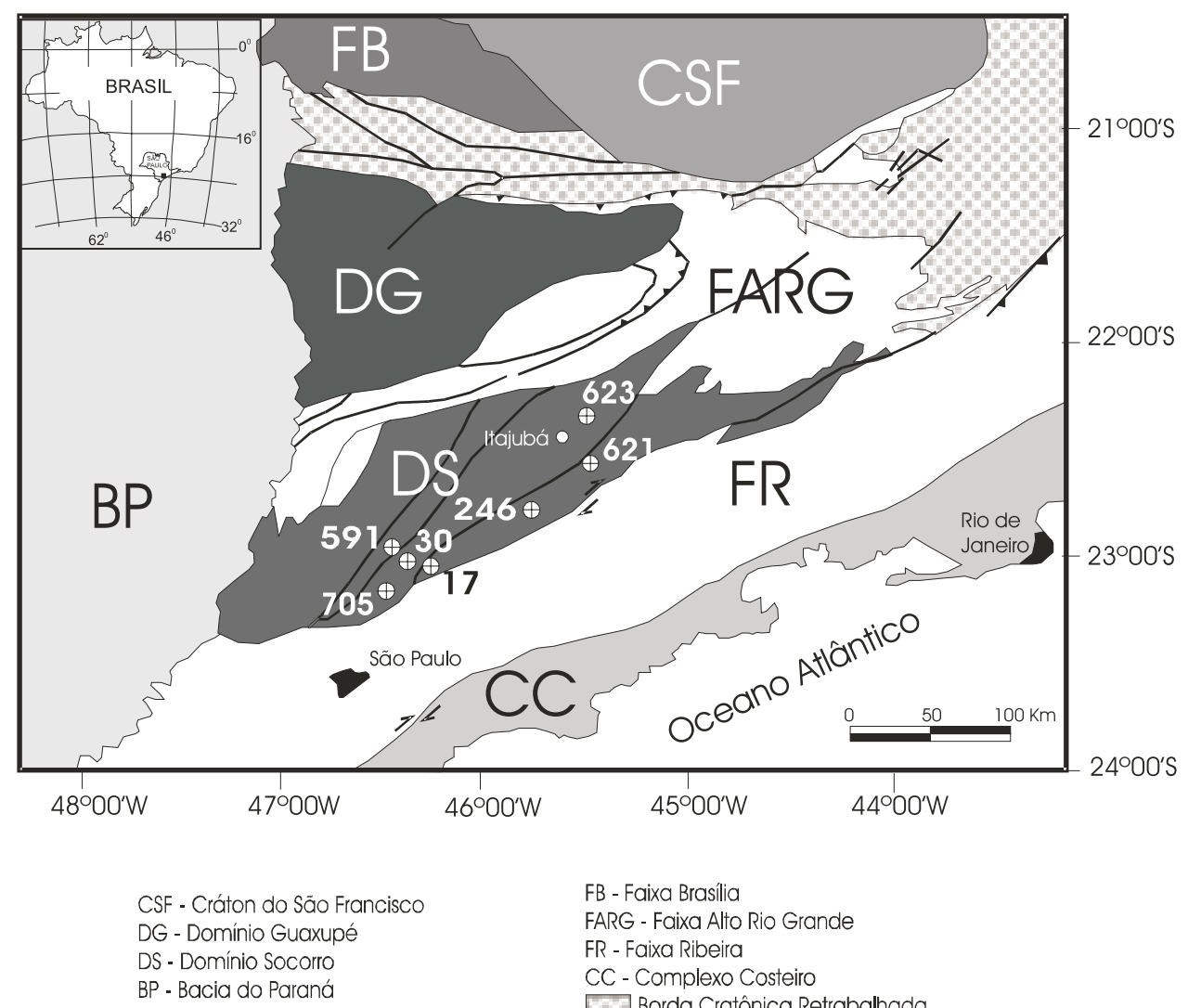

FB - Faixa Brasília

FARG - Faixa Alto Rio Grande

FR - Faixa Ribeira

CC - Complexo Costeiro

Borda Cratônica Retrabalhada

Figura 1. Localização das ocorrências cálcio-alcalinas pré-colisionais (entre 660 e 640 Ma) no Domínio Socorro, Província Mantiqueira Central (modificado de Morais et al., 1999). H621 (22 $\left.{ }^{\circ} 30^{\prime} \mathrm{S} / 4^{\circ} 22^{\prime} \mathrm{W}\right) ; \mathrm{H} 623^{\circ}\left(22^{\circ} 20^{\prime} \mathrm{S} / 45^{\circ} 21^{\prime} \mathrm{W}\right.$ ); H705

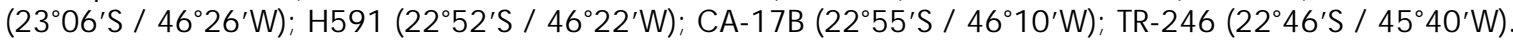




\section{GEOLOGIA REGIONAL}

A Província Mantiqueira (Almeida et al., 1981) tem em sua conceituação inicial uma evolução Brasiliana-Pan-Africana que envolve as faixas Ribeira, Araçuaí e Dom Feliciano, ao longo da costa sudeste do Brasil, incluindo litologias de diferentes origens e idades. A Faixa Brasília (FB) segue o entorno oeste do Cráton São Francisco e apresenta uma história evolutiva neoproterozóica, inicialmente independente da Faixa Ribeira (FR), seguida de processo colisional comum às duas faixas. $\mathrm{O}$ limite entre as duas faixas, ainda incerto, estaria a sudeste do Domínio Socorro (Figura 1), segundo Campos Neto (2000) marcado pela Zona de Cisalhamento Jundiuvira, representando uma grande sutura.

Rochas do embasamento da província são constituídas principalmente por orto- e paragnaisses paleoproterozóicos com ocorrências menores de rochas arqueanas (Artur, 1988; Fetter et al., 2001). Supracrustais paleoproterozóicas a neoproterozóicas representam a cobertura do embasamento, que foi intrudida por abundantes corpos plutônicos pré-, sin- e pós-colisionais durante a colagem orogênica brasiliana.

Pelo conhecimento atual sobre a evolução neoproterozóica da região, esta pode ser descrita a partir da fragmentação do continente Rodínia. Idades de sedimentação precoce registrando esta fragmentação ainda não estão definidas. Os primeiros registros de processos magmáticos e metamórficos atuando no Grupo Embu foram reportados através de idades em torno 810 a $780 \mathrm{Ma}$ (U-Pb em zircão e monazita) (Cordani et al., 2000; Vlach, 2001; Negri, 2002).

Modelos tectônicos na FR central têm sido conflitantes, sugerindo subducção para sudeste ou para noroeste (Porada 1979, Trompette, 1994; Soares et al., 1990; Wernick, 1998), ambos seguidos por colisão entre os crátons de São Francisco, Congo e do Paraná. O magmatismo pré-colisional vinculado a este processo ainda é pouco caracterizado.

Dados sobre máximos tectônicos foram descritos inicialmente por Campos Neto \& Figueiredo (1995), discriminando as orogenias Brasiliana (670 - $600 \mathrm{Ma}$ ) e Rio Doce (590 - $480 \mathrm{Ma}$ ). A partir daí seguiram-se vários trabalhos sobre a evolução da Faixa Ribeira, em sua área central.

Com base nos dados disponíveis a principal fase de colisão ocorreu entre ca. 625 e 610 Ma (Ebert et al., 1996; Janasi et al., 2001; Fetter et al., 2001), período de expressão regional envolvendo tanto a FR como a FB. Ao redor de 610 Ma teria ocorrido um processo de escape lateral, tardicolisional associado a magmatismo subalcalino entre $600 \mathrm{Ma}$ (Hackspacher \& Godoy, 1999) e $595 \mathrm{Ma}$ (Ebert et al., 1996). Localmente, em regime distensivo, registra-se a formação de retroarco por volta de $630 \mathrm{Ma}$ (Grupo São Roque), com estruturação de oceano pouco expandido (Hackspacher et al., 1999).

Ao norte, no Estado de Rio de Janeiro, a FR registra quatro fases tectônicas:

1. pré-colisional (630 - $600 \mathrm{Ma})$;

2. sin-colisional (590 - $565 \mathrm{Ma}$ );

3. tardi-colisional (540 - $520 \mathrm{Ma}$ );

4. pós-tectônico (520 - 480 Ma) (Heilbron et al., 1995; Machado et al., 1996; Trouw et. al., 2000).

A impressão do tectonismo brasiliano na FR central, especialmente os movimentos transcorrentes tardios, complicaram a determinação das relações e correlações originais entre blocos crustais e unidades geológicas (Hasui, 1983), em especial no Domínio Socorro que registra a superposição de histórias progressivas de dois sistemas orogênicos distintos: Brasília e Ribeira (Ebert \& Hasui, 1998). Na configuração atual, terrenos e níveis crustais distintos são expostos lado a lado devido a forte componente vertical (Hackspacher \& Godoy, 1999) associado a este processo transcorrente. Recentes estudos baseados em isótopos de $\mathrm{Nd}$ reconhecem a justaposição de diferentes terrenos relacionados à aglutinação e retrabalhamento na seção central da FR (Dantas et al., 1999) com pequenos blocos crustais apresentando assinaturas isotópicas $\mathrm{Sm}-\mathrm{Nd}$ distintas e particulares.

Visando caracterizar melhor o arcabouço tectônico geral da região o sistema orogênico foi subdivido em domínios ou unidades geotectônicas (Cavalcante et al., 1979; Campos Neto et al., 1990; Hasui et al., 1993; Ebert et al., 1997). Segundo a síntese regional de Morais et al., 1999, a parte central da Província Mantiqueira nesta região é dividida nos domínios Faixa Alto Rio Grande, Socorro, São Roque, e Embu (Figura 1). O Domínio Socorro é considerado como entidade pertencente à FB com influência da FR.

Nesta pesquisa, rochas ígneas deformadas e gnaissificadas dos complexos Piracaia e Paraisópolis no Domínio Socorro foram amostradas para a execução de estudos geocronológicos pelos métodos $\mathrm{U} / \mathrm{Pb}$ e $\mathrm{Sm} / \mathrm{Nd}$. Segundo Morais et al. (1999), o Complexo Paraisópolis é constituído por:

a. migmatitos anatéticos com estruturas diversas freqüentemente polifásicos, com neossoma granítico a granodiorítico e restitos anfibolíticos e biotíticos e paleossoma de ortognaisses tonalíticos, trondhjemíticos e granodioríticos; biotita gnaisses porfiroclásticos e intercalações de metassedimentos; rochas máficas e ultramáficas 
com ou sem hiperstênio, maciças ou gnaissificadas;

b. gnaisses granulíticos charnoquíticos a enderbíticos; rochas maciças de mesma composição; gnaisses granulíticos diversos; hornblenda-granada granulitos mesocráticos a melanocráticos, milonitizados;

c. granada-hornblenda-biotita gnaisses bandados, com magnetita, milonitizados com níveis anfibolíticos e localmente rochas ultrabásicas. O Complexo Piracaia aflora na Folha Guaratinguetá (1.250.000), numa extensa faixa de direção NE-SW, a sul e sudoeste do Complexo Paraisópolis, sendo constituído por xistos e gnaisses biotíticos, localmente com silimanita, granada e cordierita; muscovita quartzitos feldspáticos, rochas calciossilicáticas, mármores, gonditos, (hornblenda)-biotita gnaisses bandados e ortognaisses graníticos a granodioríticos. Localmente apresentam intercalações de rochas granulíticas (Campos Neto et al., 1983).

\section{GEOLOGIA DOS CORPOS GRANÍTICOS SIN- A PÓS- COLISIONAIS}

A distribuição de corpos graníticos neoproterozóicos ao longo da FR é extensa e geneticamente complexa ocorrendo desde o Complexo Costeiro até os domínios Socorro e Guaxupé. Estes mostram tipos ou suítes bem definidas com relações petrográficas e estruturais marcantes (Hasui et al., 1978; Godoy, 1989; Janasi \& Ulbrich, 1991; Artur et al., 1991; Machado \& Damange, 1996; Galembeck 1997; Wernick, 1998; Janasi et al., 2001). A geocronologia U-Pb em zircão tem permitido subdividir tais conjuntos em fases magmáticas bem mais restritas e definidas no tempo.

De acordo com os dados disponíveis até o momento a principal fase de granitogênese está relacionada ao processo sin-colisional de 630 - 620 Ma nos domínios Socorro e Guaxupé (Töpfner, 1996; Hackspacher et al., 1999; Hackspacher et al., 2000) e aos corpos de Piedade/Ibiúna e Cachoeira, entre outros. Janasi (1999) define uma fase principal de metamorfismo em $625 \mathrm{Ma}$, relacionada a este processo colisional, a partir da datação de monazitas do granito anatético de Nazaré Paulista. Este processo parece ser correlato ao metamorfismo principal de alto-grau da parte sul da FB, datado em torno de $630 \mathrm{Ma}$ (Pimentel et al., 2000).

Segue-se a fase sin- a tardi-colisional, com os corpos graníticos de Piedade/Ibiúna, Cachoeira, Três Córregos etc, na FR (Domínio Embu), com idades em torno de 610 Ma e no Domínio Socorro-Guaxupé, com idades semelhantes (Ebert et al., 1996; Töpfner, 1996; Fetter et al., 2000; Janasi et al., 2001) e com alojamento de sienitos potássicos derivados de mantos enriquecidos (Janasi et al., 1993).
Vinculados à fase tardi-colisional ou de escape lateral ocorrem representantes de magmatismo cálcio-alcalino a alcalinos do tipo I, nos maciços graníticos São Roque, Sorocaba e São Francisco e, localmente S, no Maciço São Roque (Godoy, 1989) no Domínio São Roque, e Serra do Lopo, no Domínio Socorro.

Granitos cálcio-alcalinos de alto K e granitos aluminosos do tipo A, pós-orogênicos, com idades ao redor de $580 \mathrm{Ma}$ (Vlach et al., 1990), foram descritos por Töpfner (1996), Galembeck (1997), e Wernick (1998), entre outros.

\section{EVIDÊNCIAS DE MAGMATISMO PRÉ- COLISIONAL NO DOMÍNIO SO CORRO}

Idades de magmatismo de $c a$. 650 Ma na Província Mantiqueira apenas recentemente vêm sendo reportadas na comunidade científica. Este valor era considerado no contexto das idades brasilianas sem nenhum destaque especial. Contudo, com o recente incremento de dados geológicos e geocronológicos sobre granitóides colisionais (e.g. Janasi et al., 2001), ficou flagrante a existência de idades mais antigas, no intervalo acima mencionado: $652 \mathrm{Ma}$ por $\mathrm{Rb} / \mathrm{Sr}$ em rocha total em granito (TR-246, Figura 1) aproximadamente $7 \mathrm{~km}$ a SW de Campos do Jordão (Santoro et al., 1998); 655 Ma por U-Pb (H591, Figura 2) em zircão de migmatito do Complexo Socorro (Ebert et al., 1996); $649 \mathrm{Ma}$ através de $\mathrm{Pb}$ - $\mathrm{Pb}$ em zircão em granodiorito gnáissico (CA17, Figura 1) da suíte São Francisco Xavier (aproximadamente10 km E-SE de Extrema) (Negri \& Oliveira, 2001).

Estes dados estimularam a coleta e datação pelos métodos $\mathrm{U} / \mathrm{Pb}$ e $\mathrm{Sm} / \mathrm{Nd}$ de outros corpos graníticos, cujas características petrográficas e estruturais poderiam ser interpretadas como relacionados a uma fase pré-colisional.

Registre-se ainda um evento de magmatismo mais antigo no Complexo Embu (Cordani et al., 2000; Vlach, 2001; Cordani et al., 2002), sugerindo que a convergência durante a orogênese Brasiliana pode ter começado já no neoproterozóico médio.

\section{MÉTODOS ANALÍTICOS}

Dados analíticos U-Pb para esta investigação foram obtidos no Instituto de Geociências da Universidade de São Paulo (IGc/USP) em 2000 e no Instituto de Geociências da Universidade de Brasília (IG/UnB) em 2001. As amostras foram preparadas para análises no Instituto de Geociências e Ciências Exatas da Universidade Estadual Paulista (IGCE/ UNESP) em Rio Claro. 

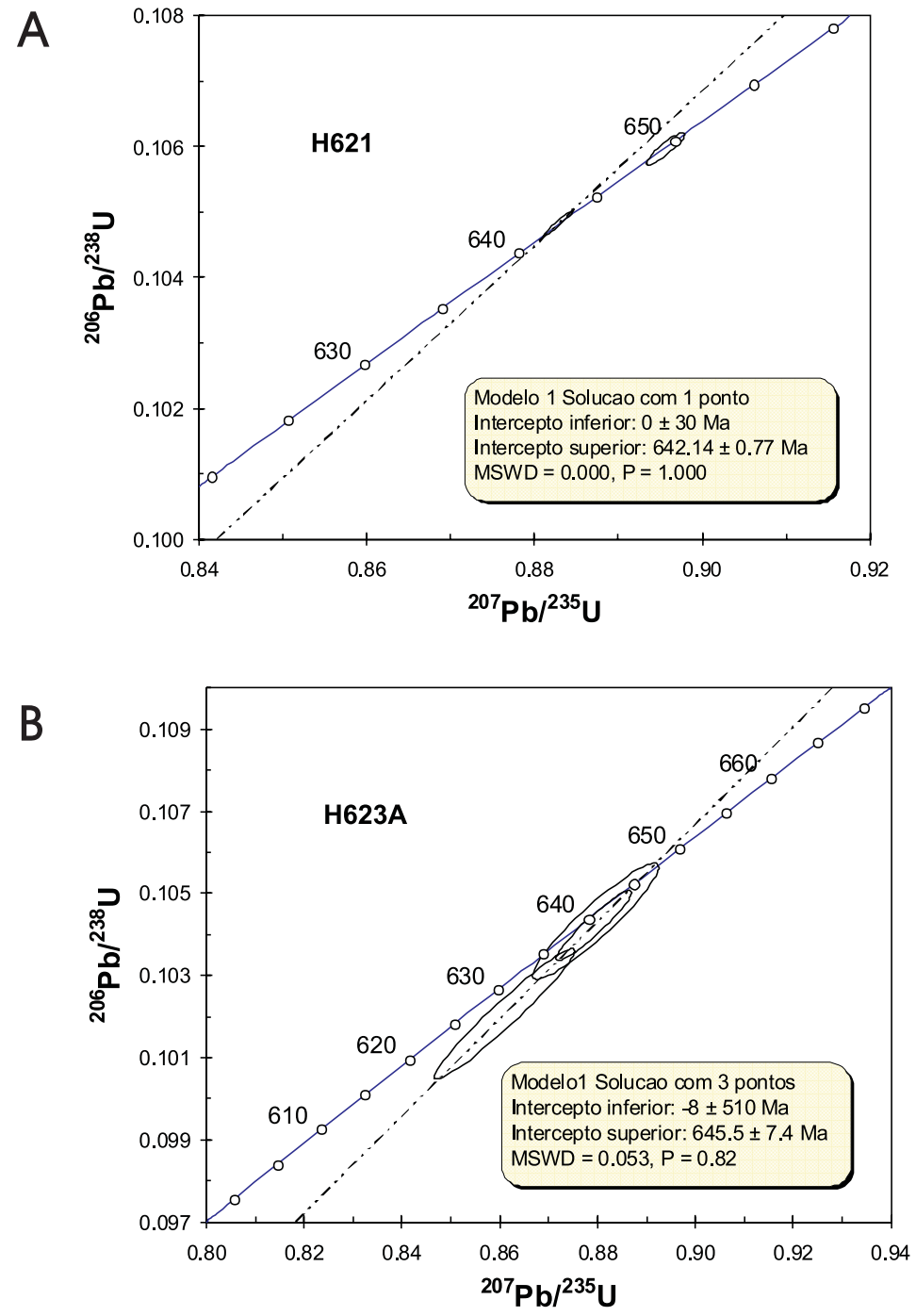

Figuras $2 \mathrm{~A}$ a $2 \mathrm{C}$. Diagramas convencionais de concórdia U-Pb mostrando regressões dos dados analíticos das unidades plutônicas pré-colisionais dentro dos complexos Paraisópolis e Piracaia do Domínio Socorro. Os dados analíticos encontram-se na Tabela 1 e a localização das amostras está na Figura 1.

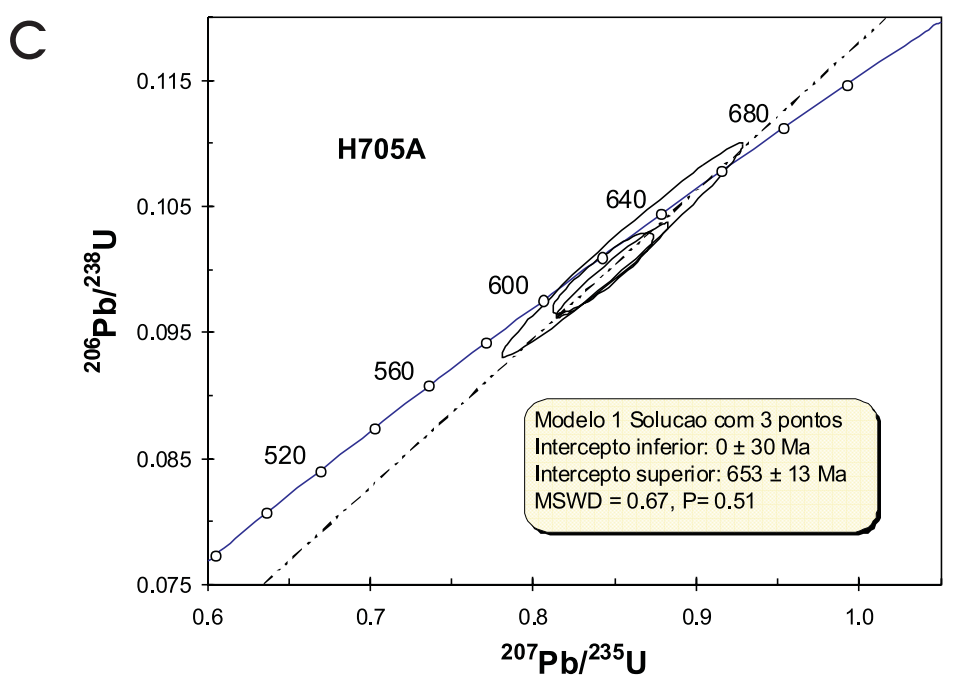


Para os estudos tomaram-se frações de monocristais e/ ou frações diminutas de multigrãos de zircão, selecionadas e dissolvidas, com o $\mathrm{Pb}$ e U purificados, seguindo procedimentos modificados de Krogh (1973 e 1982) e Parrish (1987). Foi adicionado o traçador (spike) de ${ }^{205} \mathrm{~Pb}^{235} \mathrm{U}$ (USP205-D) às amostras solubilizadas. A medição foi feita em espectrômetros de massas Finnigan 262 do IGc/USP e do IG/UnB. As médias modais analíticas das razões isotópicas foram obtidas através de contagens com coletor iônico simples ou com multicoletor em modo estático, dependendo da intensidade do sinal obtido. As amostras foram depositadas em filamentos simples de Re com sílica gel e ácido fosfórico. As composições isotópicas de $\mathrm{Pb}$ foram corrigidas para fracionamento de massa de $0,12 \% \pm 0,05$ por unidade de massa atômica para análises feitas com multicoletor e $0,18 \% \pm 0,05$ por unidade de massa atômica para coletor iônico simples (baseado em várias análises de padrão de $\mathrm{Pb}$ SRM 981). O fracionamento de $\mathrm{U}$ foi determinado através de várias análises do SRM U-500. Variações nas razões $\mathrm{U} / \mathrm{Pb}$ devido às incertezas no fracionamento isotópico e espectrometria de massa foram de aproximadamente $\pm 0,5 \%$, contudo, em alguns casos atingiram até $2 \%$ para amostras muito pequenas. Isótopos de $\mathrm{Pb}$ radiogênico foram corrigidos para os brancos analíticos de $\mathrm{Pb}$ ( $\mathrm{Pb}$ moderno) e para $\mathrm{Pb}$ inicial (não radiogênico) segundo o modelo de Stacey e Kramers (1975), para a idade próxima da idade da amostra. Constantes de decaimento utilizadas são aquelas publicadas por Steiger \& Jäger (1977). Os brancos analíticos variaram entre 11 e 46 pg para $\mathrm{Pb}$ e 0,5 e 4 pg para U. Dados U-Pb em zircão (Tabela 1) foram tratados através do programa Isoplot/Ex (Ludwig, 1999). Em dois casos (Figuras 2Ae 2C), as regressões foram forçadas para zero por causa da proximidade dos pontos da concórdia e no outro (Figura 2B) forneceu uma solução de modelo $1(\mathrm{P}=82 \%)$.

Para análises Sm-Nd em rocha total $c a .150 \mathrm{mg}$ de rocha homogeneamente pulverizada foram colocadas em "bombas" de $23 \mathrm{ml}$ (Teflon PTFE - Parr) com um traçador ${ }^{149} \mathrm{Sm} /{ }^{150} \mathrm{Nd}$. Em seguida, uma etapa de pré-dissolução foi feita com adição de aproximadamente $4 \mathrm{ml}$ de $\mathrm{HF}: \mathrm{HNO}_{3}$ 5:1 a frio durante uma noite. No dia seguinte procedeu-se a evaporação desta solução em chapa aquecedora (aproximadamente $125^{\circ} \mathrm{C}$ ) por algumas horas. Para conseguir dissolução total, foram adicionados mais $5 \mathrm{ml}$ de solução $\mathrm{HF}: \mathrm{HNO}_{3}$ 5:1 à bomba e à mistura aquecida em forno de microondas convencional por 1 minuto e meio (potência 40\%) (modificado de Patchett \& Ruiz, 1987). Elementos terras raras foram inicialmente separados utilizando colunas com resina de troca iônica (Bio-Rad) de 100 a 200 mesh (AG50W-X8) em um meio $\mathrm{HCl}$. Sm e $\mathrm{Nd}$ foram separados pela técnica de troca iônica, baseado no método de Richard et al. (1976), White \& Patchett (1984) e Patchett \& Ruiz (1987), empregando resina EiChrom LN-SPEC (100 a 200 mesh). As medidas isotópicas foram feitas no IGc-USP segundo os métodos descritos em Sato et al. (1995).

Tabela 1. Dados U-Pb em zircões do Domínio Socorro.

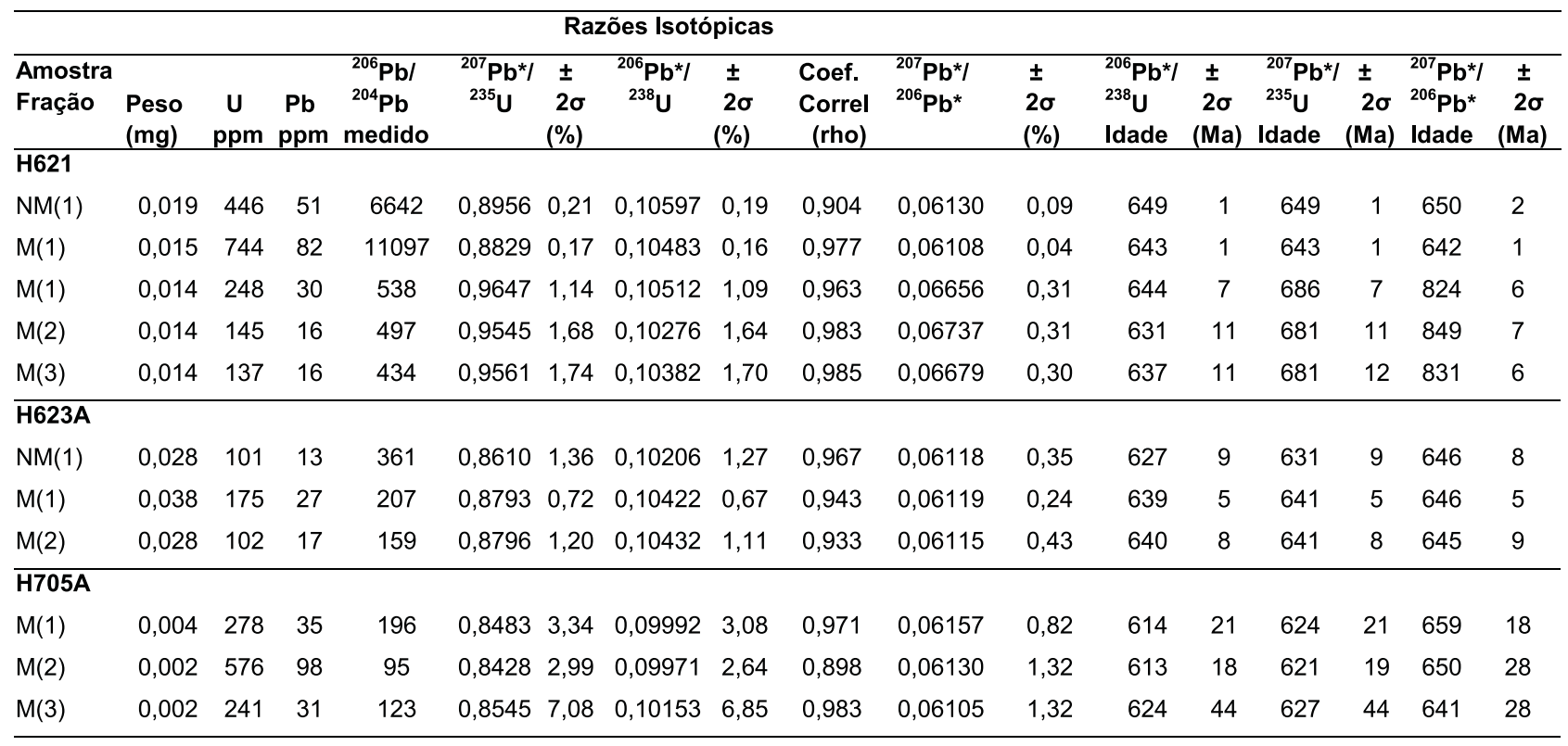




\section{RESULTADOS U-Pb}

\section{Registros de magmatismo entre 660 e 640 Ma no Domínio Socorro}

A amostra H621 é proveniente da região sudeste de Itajubá. Trata-se de um gnaisse granítico milonítico pertencente ao Domínio Socorro situado entre as zonas de cisalhamento São Bento do Sapucaí e Sapucaí-Mirim. O gnaisse é cinza, finamente bandado, alternando quartzo, plagioclásio, K-feldspato, biotita, muscovita e minerais acessórios. Localmente apresenta segregação centimétrica rósea composta principalmente por K-feldspato. Sua composição modal é de monzogranito e sua composição química indica tratar-se de material cálcio-alcalino peraluminoso (Braga, 2002). A rocha tem estrutura bandada subvertical com feições miloníticas e lineação de estiramento direcional típicas das zonas de cisalhamento transcorrentes desta região, além de indicadores de rejeito dextral. Porfiroclastos de feldspato potássico e plagioclásio foram rotacionados em matriz de quartzo, plagioclásio (andesina-oligoclásio), biotita, muscovita e minerais acessórios.

Os cristais de zircão desta amostra são amarelos, euédricos e prismáticos, com relação geométrica (comprimento:largura) de, aproximadamente, 4:1. Cinco frações (monocristais) de zircão foram analisadas fornecendo dois pontos concordantes em $642 \pm 1 \mathrm{Ma}$ e $650 \pm 2 \mathrm{Ma}$ (Figura $2 \mathrm{~A}$ ), e três pontos discordantes com idades ${ }^{207} \mathrm{~Pb} /{ }^{206} \mathrm{~Pb}$ entre 824 e $849 \mathrm{Ma}$ (Tabela 1). Interpreta-se a idade de cristalização como sendo de 642 Ma pelos seguintes motivos:

1. as idades ${ }^{207} \mathrm{~Pb} / 206 \mathrm{~Pb}$ entre 824 e 849 Ma representam frações de zircões herdados ou herança nos núcleos;

2. a idade 650 Ma provavelmente representa um cristal herdado de uma unidade local gerada durante magmatismo regional de 660 a $640 \mathrm{Ma}$.

A presença de três frações de cristais com idades do Neoproterozóico Médio, nesta rocha, tem implicações interessantes. A existência de cristais com uma idade em torno de 824 Ma pode significar derivação de uma fonte idêntica, sendo que o magmatismo reconhecido no Complexo Embu por Cordani et al. (2000, 2002) e Vlach (2001), pode representar uma entidade maior, de possível reconhecimento e caracterização em outros domínios. Contudo, tais idades podem representar valores híbridos entre zircão paleoproterozóico e neoproterozóico no mesmo cristal.

A amostra H623A é proveniente da região de Maria da Fé. Trata-se de um granulito básico do Complexo Paraisópolis de coloração cinza escura, granulação fina a média, foliado, alternando bandas máficas de piroxênio (augita/diopsídio) em núcleos de anfibólio e biotita e leitos com quartzo e plagioclásio (An 28 a 45). Sua composição química evidencia uma rocha de afinidade cálcio-alcalina meta-aluminosa (Braga, 2002). Apresenta foliação com baixo mergulho (230/15) e é cortado por veios de leucossoma (H623B).

Os cristais de zircão desta rocha consistem de cristais transparentes com morfologias anedrais e irregulares. Estas formas são tipicamente observadas em rochas mais máficas e são interpretadas como resultante de cristalização tardia na matriz da rocha (e.g. Poldervaart, 1956). Por causa da formação tardia deste tipo de cristais, eles são quase sempre livres de herança isotópica. Três frações (4 grãos cada) de zircões forneceram pontos analíticos quase concordantes. Os três pontos forçados a zero definem uma idade de $646 \pm 7 \mathrm{Ma}$ (Figura 2B), interpretada como a idade de cristalização magmática da rocha.

A amostra H705B provém da Pedreira Batatuba, localizada cerca de $5 \mathrm{~km}$ a sudoeste da cidade de Piracaia. Trata-se de um pequeno corpo de ortognaisse cinza-médio, homogêneo, de composição granítica, com fases locais charnockíticas, aparentemente intrusivo em um pacote metassedimentar migmatítico do Complexo Metamórfico Piracaia (Campos Neto et al., 1983). A amostra H705B é um charnockito gnáissico, inequigranular, grosso, de cor cinzaesverdeada, portador de ortopiroxênio, hornblenda e biotita, cuja composição química permite classificá-lo no campo cálcio-alcalino.

Cristais de zircão desta rocha são dominados por uma população homogênea; cristais transparentes e amarelos claros, euedrais e prismáticos que exibem aspectos geométricos (comprimento:largura) de aproximadamente 4:1. Três monocristais de zircão desta amostra forneceram pontos próximos da concórdia, e forçados para zero definem uma idade de $653 \pm 13 \mathrm{Ma}$ (Figura 2), interpretada como a idade do protólito ígneos. Por causa da dimensão dos grãos ( 2 a 4 microgramas cada) e baixo teor de $\mathrm{Pb}$, os erros analíticos são bastante elevados em comparação com aqueles das demais amostras analisadas. Mesmo assim, esta idade é consistente com a de outros corpos da região, como o gnaisse migmatítico próximo à cidade de Extrema (Figura 1) que forneceu uma idade U-Pb de $655 \pm 2 \mathrm{Ma}$ (Ebert et al., 1996) e um gnaisse granodiorítico da suíte São Francisco Xavier localizados a aproximadamente $45 \mathrm{~km}$ ao nordeste datado em $649 \pm 4$ Ma por Negri e Oliveira (2001).

Os novos dados obtidos neste trabalho mostram que o evento magmático em torno de 650 Ma tem distribuição regional, estando registrado em diferentes maciços geograficamente separados por zonas de cisalhamento transcorrentes relacionadas à história tardia da evolução da FR. 


\section{Registros de magmatismo entre 850 - $780 \mathrm{Ma}$ fora do Complexo Embu}

Três frações de zircão (monocristrais) herdadas da amostra H621 (Tabela 1) forneceram idades ${ }^{207} \mathrm{~Pb} /{ }^{206} \mathrm{~Pb}$ entre $824 \mathrm{e}$ 849 Ma. Existem duas explicações para este fenômeno:

1. os cristais representam zircões derivados de uma rocha com uma idade entre 824 e $850 \mathrm{Ma}$, ou

2. os cristais representam herança de uma mistura de núcleos de ca. 2,1 Ga com sobrecrescimento de zircão de $642 \mathrm{Ma}$. Este problema pode ser solucionado com estudos de cátodo-luminescência e/ou análises U-Pb por SHRIMP (Super High Resolution Microprobe).

Cristais de zircão da amostra CA-30 (Figura 1) de gnaisse granítico a granodiorítico migmatítico (intrusivo no Complexo Piracaia) foram analisados pelo método de evaporação de $\mathrm{Pb}$ em monocristais por Negri (2002). Várias análises $\mathrm{Pb}-\mathrm{Pb}$ forneceram uma idade precisa ${ }^{207} \mathrm{~Pb} /{ }^{206} \mathrm{~Pb}$ de $780 \pm 5 \mathrm{Ma}$. Uma análise convencional U-Pb em zircão (monocristal) também foi feita fornecendo um ponto bastante discordante (Tabela 1), mas consistente com os resultados $\mathrm{Pb}-\mathrm{Pb}$.

Se compararmos os valores obtidos nestes granitóides com os de rochas do Complexo Embu, $100 \mathrm{~km}$ a SE, (Cordani et al., 2002), verifica-se a possibilidade do magmatismo do intervalo 810 a 780 Ma ter atingido outros domínios na FR. As investigações geocronológicas nesta região revelam uma história geológica neoproterozóica muito mais complexa do que considerada anteriormente, em especial para a fase précolisional.

\section{RESULTADOS ISOTÓPICOS Sm-Nd}

As unidades pré-colisionais neoproterozóicas identificadas neste estudo exibem assinaturas híbridas de $\mathrm{Nd}$, com valores $\mathrm{T}_{\mathrm{DM}}$ entre 1,39 e 1,88 Ga (Tabela 2 e Figura 1). Em contraste, muitos granitóides colisionais da FR exibem assinaturas de $\mathrm{Nd}$ próximos com os ortognaisses paleoproterozóicos cujos valores $\mathrm{T}_{\mathrm{DM}}$ situam-se entre 1,80 a 2,20 Ga (Dantas et al., 2000). Estes valores mostram claramente que os magmas dos protólitos não foram derivados somente da crosta/litosfera paleoproterozóica, e podem representar misturas entre fontes neo- e paleoproterozóica. Esta é uma característica observada em ambientes de arcos continentais por causa das interações entre magmas juvenis e componentes enriquecidos (litosfera mais antiga) em margens ativas (e.g. DePaolo, 1981, 1988; Asmeron et al., 1991; Ducea, 2001).

\section{INTERPRETAÇÃO DOS RESULTADOS E IMPLICAÇÕES GEODINÂMICAS}

Idades U-Pb entre 660 e 640 obtidas em cristais de zircão de uma série de gnaisses e plútons cálcio-alcalinos, no sudeste da Província Mantiqueira Central, sugerem que um importante período de magmatismo pré-colisional ocorreu nesta região, precursor do metamorfismo principal dos corpos ígneos de caráter sin-colisional durante a amalgamação do Gondwana Ocidental. Os dados apresentados, ao lado das informações disponíveis na literatura, permitem reconhecer a seguinte evolução para a parte central da Faixa Ribeira e sul da Faixa Brasília:

Tabela 2. Dados Sm-N d em rocha total dos maciços pré-colisionais do Domínio Socorro.

\begin{tabular}{llllllllll}
\hline Amostra Rocha & $\begin{array}{l}\mathbf{N d} \\
(\mathbf{p p m})\end{array}$ & $\begin{array}{l}\mathbf{S m} \\
(\mathbf{p p m})\end{array}$ & ${ }^{147} \mathbf{S m} /{ }^{144} \mathbf{N d}$ & $\begin{array}{l}{ }^{143} \mathbf{N d} /{ }^{144} \mathbf{N d} \\
(\mathbf{2} \mathbf{s i g m a})\end{array}$ & $\begin{array}{l}\boldsymbol{E}_{\mathbf{N d}} \\
(\mathbf{0})\end{array}$ & $\begin{array}{l}\mathbf{T}_{\mathrm{DM}} \\
(\mathbf{G a})\end{array}$ & $\begin{array}{l}\mathbf{U} / \mathbf{P b} \\
(\mathbf{G a})\end{array}$ & $\begin{array}{l}\boldsymbol{E}_{\mathbf{N d}} \\
(\mathbf{T})\end{array}$ \\
\hline H591A & paleoss. migmatito & 19,29 & 24,47 & 0,1402 & 0,511812 & $-16,1$ & 2,58 & 0,66 & $-11,3$ \\
H591B & gnaisse cinza & 12,57 & 65,54 & 0,1160 & $0,511988(10)$ & $-12,7$ & 1,63 & 0,66 & $-6,0$ \\
H591C & leucossoma & 14,54 & 107,72 & 0,0816 & $0,511405(34)$ & $-24,0$ & 1,88 & 0,66 & $-14,6$ \\
H621 & granito & 48,57 & 8,51 & 0,1060 & 0,511921 & $-14,0$ & 1,59 & 0,64 & $-6,6$ \\
H623A & enderbito & 24,13 & 5,61 & 0,1407 & 0,512157 & $-2,4$ & 1,85 & 0,65 & $-4,7$ \\
H623B & leucossoma & 20,43 & 2,07 & 0,0612 & 0,511651 & $-19,3$ & 1,39 & 0,65 & $-8,0$ \\
H705B & granito gnaisse & 35,28 & 6,10 & 0,1045 & $0,511608(14)$ & -20.1 & 1,99 & 0,65 & $-12,5$ \\
\hline
\end{tabular}

Obs.: $\mathrm{T}_{\mathrm{DM}}$ para amostras H591A e H623A são superestimadas por causa da alta razão de $\mathrm{Sm} / \mathrm{Nd}\left({ }^{147} \mathrm{Sm} /{ }^{144} \mathrm{Nd}>0,125\right)$. Cálculo das idades modelo $T_{D M}$ segundo DePaolo (1981). 
1. um estágio inicial do Ciclo Brasiliano, há aproximadamente 810 - $780 \mathrm{Ma}$, representado por magmatismo e metamorfismo no Complexo Embu, Itapira e sucessões correspondente em rochas contendo zircões detríticos ou núcleos herdados de 700 - $750 \mathrm{Ma}$, encontrados em outras unidades supracrustais regionais;

2. subducção de litosfera oceânica para oeste, durante a fase pré-colisional entre 660 e $640 \mathrm{Ma}$, com geração dos plútons cálcio-alcalinos, tipo arco de ilhas com contribuição de material mais antigo (detrítico, proveniente do cráton) ou continental (cordilherano) por subducção vinculada à FR ou FB.

3. fase sin-colisional com a formação de um magmatismo em torno de $620 \mathrm{Ma}$ associado à migmatização e plutonismo cálcio-alcalino. A fase sin-colisional, na região estudada tem uma evolução mais antiga, quando comparada à parte setentrional da FR, confirmando o diacronismo da evolução dos cinturões orogênicos. No momento, não é possível concluir se esta fase envolveu qualquer terreno exótico. Idades modelos $\mathrm{T}_{\mathrm{DM}}$ nos granitos relacionados à fase sin-colisional mostram valores entre 1,9-2,0 Ga, sugerindo a existência de fontes crustais no Paleoproterozóico;

4. segue a fase sin- a tardi-colisional até $610 \mathrm{Ma}$ com mudança de regime colisional para escape lateral;

5. a fase extensional é representada por retroarco continental com a formação de um oceano raso restrito, com vulcanismo máfico submarino, observado nos grupos São Roque e Açungui, entre 628 e $614 \mathrm{Ma}$;

6. a fase tardi-colisional, ao redor de 600 - 595 Ma é caracterizada através de tectônica de fuga lateral com as zonas de cisalhamento nordeste-sudoeste e posicionamento de corpos graníticos;

7. a fase pós-tectônica é representada pelo granito de Itu (Província Rapakivi) há 580 Ma e o começo da fase extensional e estruturação da futura Bacia de Paraná.

Conclui-se que o magmatismo de 660 - 640 Ma pode representar magmatismo de arco continental como resultado de subducção de crosta oceânica neoproterozóica, durante convergência pré-colisional precursora ao fechamento do Oceano de Adamastor se o vínculo for com a FR, ou então do Oceano Goianides se vinculado à FB.

\section{AGRADECIMENTOS}

Este estudo tornou-se possível através de concessões da FAPESP(Processo 00/05670-4) e CNPq (Processo 52.2388/ 95-7), a quem os autores expressam a sua gratidão. Somos gratos também às sugestões e correções dos revisores.

\section{REFERÊNCIAS BIBLIOGRÁFICAS}

ALMEIDAF. F. M.; HASUI, Y.; BRITO NEVES, B. B.; FUCK, R. A. (1981) Brazilian structural provinces: an introduction. Earth Sciences Review, v. 17, p. 1-29.

ARTUR, A. C. (1988) Evolução policíclica da infraestrutura da porção sul do Estado de Minas gerais e regiões adjacentes do Estado de São Paulo. São Paulo, 215 p. Tese (Doutorado) - Instituto de Geociências, Universidade de São Paulo.

ARTUR, A. C.; EBERT, H. D.; WERNICK, E. (1991) Magmatismo e tectônica no Complexo Socorro (SP/MG). In: SIMPÓSIO DE GEOLOGIA DO SUDESTE, 2., São Paulo, 1991. Boletim de Resumos. São Paulo, SBG, p. 105-110.

ASMERON, Y.; PATCHETT, P. J.; DAMON, P. E. (1991) Crust-mantle interaction in continental arcs: inferences from the Mesozoic arc in the southwestern United States. Contributions to Mineralogy and Petrology, v. 107, p. 124-134.

BRAGA, I. F. (2002) Análise deformacional de rochas infracrustais da região de Cristina e Itajubá- $M G$. Rio Claro, 197 p. Tese (Doutorado) - Instituto de Geociências e Ciências Exatas, Universidade Estadual Paulista.

CAMPANHA G. A. (1991) Tectônica Proterozóica no Alto e Médio Vale do Ribeira, Estados de São Paulo e Paraná São Paulo. São Paulo, 296 p. Tese (Doutorado) - Instituto de Geociências, Universidade de São Paulo.

CAMPANHA G. A; SADOWSKI G. R. (1999) Tectonics of the southern portion of the Ribeira Belt (Apiaí Domain). Precambrian Research, v. 98, p. 31-51.

CAMPOS NETO, M. C.; BASEI, M. A. S. (1983) Evolução estrutural brasiliana do nordeste de São Paulo: dobramentos superpostos e esboço estratigráfico e tectônico. In: SIMPÓSIO REGIONAL DE GEOLOGIA, 4., São Paulo, 1983. Atas. São Paulo, SBG, p. 61-78.

CAMPOS NETO, M. C.; BASEI, M. A. S.; ARTUR, A. C.; SILVA, M. E.; MACHADO, R.; DIAS NETO, C. M.; FRAGOSO CESAR, A. R. (1983) Geologia das Folhas Piracaia e Igaratá. In: JORNADA SOBRE A CARTA GEOLÓGICADO ESTADO DE SÃO PAULOEM 1:50.000, 1., São Paulo, 1983. Atas. São Paulo, Prominério. p. 61-78.

CAMPOS NETOM.; FIGUEIREDO, M. (1995) The Rio Doce Orogeny, southeastern Brazil. Journal South America Earth Sciences, v.8, p.143-162.

CAMPOS NETO, M. C. (2000) Orogenic systems from southwestern Gondwana: an approach to Brasiliano-Pan African cycle and collage in southeastern Brazil. In: CORDANI, U. G.; MILANI, E. J.; THOMAZFILHO, A.; 
CAMPOS, D. A. (eds.) Tectonic evolution of South America. Rio de Janeiro, p. 335-365.

CAVALCANTE, J. C.; CUNHA, H. C. S.; CHIEREGATI, L. A.; KAEFER, L. Q.; ROCHA, J. M.; DAIXT, E. C.; COUTINHO, M.G. N.; YAMAMOTO, K.; DRUMOND, J. B. V.; ROSA, D. B.; RAMALHO, R. (1979) Projeto Sapucaí: estados de São Paulo e Minas Gerais. Brasília, DNPM/CPRM, 299p. (Relatório Final).

CORDANI, U. G.; SATO, K.; TEIXEIRA, W.; TASSINARI, C. C. G.; BASEI, M. A. S. (2000) Crustal evolution of the South American platform. In: CORDANI, U. G.; MILANI, E. J.; THOMAZ FILHO, A.; CAMPOS, D. A. (eds.) Tectonic evolution of South America. Rio de Janeiro, p. $19-40$.

CORDANI, U. G.; COUTINHO, J. M.V.; NUTMAN, A. P. (2002) Geochronological constraints on the evolution of the Embu Complex, São Paulo, Brazil. Journal of South American Earth Sciences, v. 14, p. 903-910.

DANTAS, E.; HACKSPACHER, P.C.; GODOY,A. M.; SATO, K.; PIMENTEL, M.; OLIVEIRA, M. A. F.; FETTER, A. (1999) Characterization of the generating sources of continental crust of the Ribeira belt through isotope of Nd in the State of São Paulo, SE of Brazil. In: SOUTH AMERICAN SYMPOSIUMON ISOTOPE GEOLOGY, 2., Córdoba, 1999. Comunicaciones. Córdoba, Dirección de Minas y Geología, p. 192-195.

DEPAOLO, D. J. (1981) A neodymium and strontium isotopic study of the Mesozoic calc-alkaline granitic batholiths of the Sierra Nevada and Peninsular Ranges, California. Journal of Geophysical Research, v. 86, p. 10470-10488.

DUCEA, M. (2001) The California Arc: thick granitic batholiths, eceologitic residues, Lithospheric-Scale thrusting, and magmatic Flare-Ups. GSA Today, v. 11, n. 11, p. 4-10.

EBERT, H. D.; CHEMALE JR., F.; BABINSKY, M.; ARTUR, A. C.; VAN SCHMUS, W. R. (1996) Tectonic setting and $\mathrm{U} / \mathrm{Pb}$ zircon dating of the plutonic Socorro Complex in the Transpressive Rio Paraíba do Sul Shear Belt, SE Brazil. Tectonics, v.15, n. 3, p. 688-699.

EBERT, H. D.; MALAGUTTI FILHO, W.; HASUI, Y.; HARALYI, N. E.; HACKSPACHER, P. C.; MORALES, N.; SOUZA, C. A. (1997) Compartimentação crustal do sul de Minas Gerais a partir de dados gravimétricos e lito-estruturais. In: SIMPÓSIO NACIONAL DE ESTUDOS TECTÔNICOS, 6., Pirenópolis-GO, 1997. Anais. Brasilia, SBG, p. 31-35.

EBERT, H. D.; HASUI, Y. (1998) Transpressional tectonics and strain partitioning during oblique collision between three plates in the precambrian of south-east Brazil, In: HOLDSWORTH, R. E.; STRACHAN, R. A.; DEWEY. J. F. (eds.) Continental transpressional/transtensional tectonics. London, Geological Society. p. 231-252. (Geological Society Special Publication, n.135).

FETTER, A. H.; HACKSPACHER, P. C.; EBERT, H. D.; DANTAS, E. L.; COSTA, A. C. D. (2001) New Sm/Nd and $\mathrm{U} / \mathrm{Pb}$ geochronological constraints on the Archean to Neoproterozoic evolution of the Amparo Basement Complex of the Central Ribeira Belt southeastern Brazil. In: SOUTH-AMERICAN SYMPOSIUM ON ISOTOPE GEOLOGY, 3., Pucón, 2001. Extended Abstracts. Pucón, Sociedad Geológica de Chile, p. 36. (CD-ROM).

FIGUEIREDO M. C. H.; BERGMANN M.; PENALVA F.; TASSINARI C. C. G. (1982) Ocorrência de pillow lavas no Grupo São Roque, Estado de São Paulo. Ciências da Terra, v. 2, p. 6-8.

GODOY, A. M. (1989) Caracterização faciológica, petrográfica e geoquímica dos maciços Sorocaba e São Francisco. São Paulo, 221 p. Tese (Doutorado) - Instituto de Geociências, Universidade de São Paulo.

GALLENBECK, T. M. (1997) O Complexo Múltiplo, Centrado e Plurisserial Itu- SP. Rio Claro, 374 p. Tese (Doutorado) - Instituto de Geociências e Ciências Exatas, Universidade Estadual Paulista.

HACKSPACHER, P. C.; GODOY, A. M. (1999) Vertical displacement during late-collisional escape tectonics (Brasiliano Orogeny) in the Ribeira Belt, São Paulo State, Brazil. Journal of African Earth Sciences, v. 29, p. 25-32.

HACKSPACHER, P. C.; DANTAS E. L.; GODOY A. M.; OLIVEIRA M. A. F.; FETTER A.; VAN SCHMUS W. R. (1999) Considerations about the evolution of the Ribeira Belt in the São Paulo State - Brazil, from U/Pb geochronology in metavolcanic rocks of the São Roque Group. In: SOUTH AMERICAN SYMPOSIUM ON ISOTOPE GEOLOGY, 2., Cordoba, 1999. Comunicaciones. Córdoba, Dirección de Minas y Geología, p. 310-313.

HACKSPACHER, P. C.; DANTAS, E. L.; SPOLADORE, A.; FETTER, A. H.; OLIVEIRA, M. A. F. (2000) Evidence For Neoproterozoic backarc basin development in the Central Ribeira Belt, Southeastern Brazil: new geochronological and geochemical constraints From The São Roque Açungui Groups. Revista Brasileira de Geociências, v. 30, n. 1, p. 110-114.

HASUI, Y. (1983) Aspectos geológicos essenciais da seção Caconde-Caraguatatuba e suas implicações na reconstituição da organização e evolução do PréCambriano do leste paulista. IN: JORNADA SOBRE A CARTAGEOLÓGICADOESTADODESÃOPAULOEM 
1:50.000, 1., São Paulo, 1983. Atas. São Paulo, Prominério. p. 227-252.

HASUI, Y.; CARNEIRO, C. D. R.; BISTRICHI, C. A. (1978) Os granitos e granitóides da região de dobramentos sudeste nos Estados de São Paulo e Paraná. In: CONGRESSO BRASILEIRO DE GEOLOGIA, 30., Belo Horizonte, 1978. Anais. Belo Horizonte, SBG, v. 6, p. 2579-2593.

HASUI, Y.; HARALYI, N. L. E.; COSTA, J. B. S. (1993) Megaestruturação Pré-Cambriana do território brasileiro baseada em dados geofísicos e geológicos. Geociências, v. 12, n. 1, p. 7-31.

HEILBRON, M.; VALERIANO, C.; VALLADARES, C. S.; MACHADO, N. (1995) A Orogênese Brasiliana no segmento central da Faixa Ribeira, Brasil. Revista Brasileira de Geociências, v. 25, p. 249-266.

JANASI, V. A. (1999) Petrogênese de granitos crustais na Nappe de Empurrão Socorro-Guaxupé (SP-MG): uma contribuição da geoquímica elemental e isotópica. São Paulo, 304 p. Tese (Livre-Docência) - Instituto de Geociências, Universidade de São Paulo.

JANASI, V. A.; ULBRICH, H. G. J. (1991) Late proterozoic granitoid magmatism in the state of São Paulo, southeastern Brazil. Precambrian Research, v. 51, p. 351-374.

JANASI, V. A.; VLACH, S. R. F.; ULBRICH, H. G. J. (1993) Enriched-mantle contributions to the Itu granitoid belt, southeastern Brazil: evidence form K-rich diorites and syenites. Anais da Academia Brasileira de Ciências, v. 65, p. 107-118.

JANASI, V. A.; LEITE, R. J.; SCHMUS, W. R. (2001) U-Pb chronostratigraphy of the granitic magmatismo in the Agudos Grandes Batholith (west of São Paulo, Brazil) implications for the evolution of the Ribeira Belt. Journal of South American Earth Sciences, v. 14, p. 363-376.

JULIANI, C.; BELJAVSKIS, P.; SCHORCHER, H. D. (1986) Petrogênese do vulcanismo e In: CONGRESSO BRASILEIRODE GEOLOGIA, 34., Goiânia, 1986. Anais. Goiânia, SBG, p. 730-747.

JULIANIC.; HACKSPACHER P.C.; DANTAS E. L.; FETTER A. H. (2000) The Serra do Itaberaba Group: a Mesoproterozoic volcano-sedimentary sequence basement of São Roque Group at São Paulo State, Brazil. In: INTERNATIONAL GEOLOGICALCONGRESS, 31. Rio de Janeiro, 2000. Abstracts. Rio de Janeiro, SBG. (CDROM).

KROGH, T. E. (1973) A low contamination method for hydrothermal decomposition of zircon and extraction of $\mathrm{U}$ and $\mathrm{Pb}$ for isotopic age determinations. Geochimica et Cosmochimica Acta, v. 37, p. 485-494.
KROGH, T. E. (1982) Improved accuracy of U-Pb zircon ages by the creation of more concordant systems using an air abrasion technique. Geochimica et Cosmochimica Acta, v. 46, p. 637-649.

LUDWIG, K. R. (1999) ISOPLOT/EX - a plotting and regression program for radiogenic-isotope data: version 2.70. United States Geological Survey Open-File Report, n. 91-445, p.1-42.

MACHADO, R.; DEMANGE, M. (1996) Caracterização geoquímica e tectônica do magmatismo pré-colisional tipo cordilheirano de idade neoproterozóica no Cinturão Paraíba do Sul, Estado do Rio de Janeiro. Boletim IGUSP. Publicação Especial, v. 18, p. 83-85.

MACHADO, N.; VALLADARES, C. S.; HEILBRON, M.; VALERIANO, C. M. (1996) U-Pb geochronology of the central Ribeira belt (Brazil) and implications for the evolution of the Brazilian Orogeny. Precambrian Research, v. 79, p. 347-361.

MANIESI, V.; OLIVEIRA, M. A. F. (2000) Petrogênese dos metabasitos com afinidade dos toleítos de fundo oceânico das regiões de Adrianópolis e Campo Largo, PR. Revista Brasileira de Geociências, v. 30, n. 4, p. 607-614.

MANIESI, V.; OLIVEIRA, M. A. F.; ZANARDO, A. (1999) Petrologia do metagabro de Apiaí- dados preliminares. In: SIMPÓSIO DE GEOLOGIA DO SUDESTE, 6., São Pedro, 1999. Boletim de Resumos. São Pedro, SBG. p. 36.

MORAIS, S. M. (1999) Integração geológica da folha Guaratinguetá SF.23-Y-C, Escala 1:250 000 - Estados de São Paulo e Minas Gerais - nota explicativa. São Paulo, CPRM. 28 p. (Programa Levantamentos Geológicos Básicos do Brasil).

NEGRI, F. A. (2002) Petrologia das rochas charnockitograníticas e encaixantes de alto grau associadas na região de São Francisco Xavier, SP. Rio Claro, 404 p. Tese (Doutorado) - Instituto de Geociências e Ciências Exatas, Universidade Estadual Paulista.

NEGRI, F. A.; OLIVEIRA, M. A. F. (2001) Geochronology ${ }^{207} \mathrm{~Pb} /{ }^{206} \mathrm{~Pb}$ and $\mathrm{Rb} / \mathrm{Sr}$ and $\mathrm{Sm} / \mathrm{Nd}$ isotopic signatures of the neoproterozoic quartz-mangerite-monzogranitecharnockite São Francisco Xavier suite, Northeastern state of São Paulo, Brazil. In: SOUTH-AMERICAN SYMPOSIUM ON ISOTOPE GEOLOGY, 3., Pucón. 2001. Extended Abstracts. Pucón, Sociedad Geológica de Chile, p. 52. (CD-ROM).

OLIVEIRA, M. A. R.; MANIESI, V.; NARDY, A. J. R.; MALAGUTTI, M. I. A. (1999) Anomalias negativas de Ce em rochas metabásicas de Cajamar Grupo São Roque São Paulo. In: SIMPÓSIO DE GEOLOGIA DO SUDESTE, 
6., São Pedro, 1999. Boletim de Resumos. São Pedro, SBG, p. 32.

PARRISH, R. R. (1987) An improved micro-capsule for zircon dissolution in U-Pb geochronology. Chemical Geology, v. 66, p. 99-102.

PIMENTEL, M. M.; FUCK, R. A.; LIMA GIOIA, S. M. C. M. A. (2000) The Neoproterozoic Goiás Magmatic Arc, central Brazil: a review and new Sm-Nd isotopic data. Revista Brasileira de Geociências, v. 30, n. 1, p. 35-39.

POLDERVAART, A. (1956) Zircons in rocks. 2. Igneous rocks. American Journal of Science, v. 254, p. 521-554.

PORADA, H. (1979) The Damara-Ribeira orogen of the PanAfrican-Brasilian-cycle in Namibia (South West Africa) and Brazil as interpreted in terms of continental collision. Tectonophysics, v. 57, p. 237-265.

SANTORO, E.; SILVA, M. E.; BASEI, M. A. S. (1998) Litogeoquímica e geocronologia da suíte Serra Preta na região de Santo Antonio do Pinhal, SP. In: CONGRESSO BRASILEIRO DE GEOLOGIA, 40., Belo Horizonte, 1998. Boletim de Resumos. Belo Horizonte, SBG, p. 36.

SCHOBBENHAUS, C.; CAMPOS, D. A.; DERZE, G. R.; ASMUS, H. E. (1981) Mapa geológico do Brasil e da área oceânica adjacente incluindo depósitos minerais. 1: 2.500.000. Brasília, Departamento Nacional de Produção Mineral.

SOARES, P. C.; FIORI, A. P.; CARVALHO, S. G. (1990) Tectônica colisional oblíqua entre o Bloco Paraná e a margem sul do Cráton do São Francisco, no Maciço de Guaxupé. In: CONGRESSO BRASILEIRO DE GEOLOGIA, 36., Natal, 1990. Boletim de Resumos., Natal, SBG, v. 6, p. 2332-2342.

SANTORO, E.; ENS, H. H.; TASSINARI, C. C. G., (1992) Petrogênese e Geocronologia dos Granitos da Suíte Paiol Velho, São Paulo. In: CONGRESSO BRASILEIRO DE GEOLOGIA, 37., São Paulo, 1992. Boletim de Resumos Expandidos, São Paulo, SBG, p. 391-392.

SATO, K.; TASSINARI, C. C. G.; KAWASHITA, K.; PETRONILHO, L. (1995) O Método Geocronológico SmNd no IG-USP e suas Aplicações. Anais da Academia Brasileira de Ciências, v. 67, n. 3, p. 313-336.

STEIGER, R. H.; JÄGER, E. (1977) Subcommission on Geochronology- convention and use of decay constants in geochronology and cosmochronology. Earth and Planetary Science Letters, v. 36, p. 359-362.

TÖPFNER, C. (1996) Brasiliano-Granitoide in den Bundesstaaten São Paulo und Minas Gerais- eine vergleichende Studie. Münchner Geologische Hefte, v. A17, p.1-258.
TROMPETTE, R. (1994) Geology of western Gondwana (2000-500 Ma) Pan-African-Brasiliano aggregation of South America and Africa. Rotterdam, A. A. Balkema. $350 \mathrm{p}$.

TROUW, R.; HEILBRON, M.; RIBEIRO, A.; PACIULLO, F.; VALERIANO, C. M.; ALMEIDA, J.C. H.;TUPINAMBÁ, M.; ANDREIS, R. R. (2000) The central segment of the Ribeira Belt. In: CORDANI, U. G.; MILANI, E. J.; THOMAZ FILHO, A.; CAMPOS, D. A. (eds.) Tectonic evolution of South America. Rio de Janeiro, p. 287- 310.

VAN SCHMUS, W. R.; TASSINARI, C. C. G.; CORDANI, U.G. (1986) Estudos geocronológicos da parte inferior do Grupo São Roque. In: CONGRESSO BRASILEIRO DE GEOLOGIA, 34., Goiânia, 1986. Anais. Goiânia, SBG, v. 3, p. 1399-1406.

VLACH, S R. F. (2001) Microprobe monazite constraints for an early (ca. $790 \mathrm{Ma}$ ) Brasiliano Orogeny: the Embu Terrane, Southeastern Brazil. In: SOUTH-AMERICAN SYMPOSIUM ON ISOTOPE GEOLOGY, 3., Pucón, 2001. Extended Abstracts. Pucón, Sociedad Geológica de Chile, p. 72. (CD-ROM).

VLACH, S. R. F.; JANASI, V.A.; VASCONCELLOS, A.C. B. C. (1990) The Itú Belt: associated calc alkaline and aluminous a-type late Brasiliano granitoids in the states of São Paulo and Paraná, southern Brazil. In: CONGRESSO BRASILEIRA DE GEOLOGIA, 36., Natal, 1990. Anais. Natal, SBG, v. 4, p. 1700-1711.

WERNICK, E., (1998) The pluriserial Ribeira Magmatic System 590, SE/S Brazil and Uruguay. Revista Brasileira de Geociências, v. 28, n. 4, p. 533-542. 